\title{
ANTIDOTES; \\ AVAILABILITY AND THEIR COMPARISON WITH NATIONAL ESSENTIAL DRUG LIST IN DIFFERENT HOSPITALS OF LAHORE.
}

\footnotetext{
1. Final Year Student, Pharm-D, Institute of Pharmacy, Lahore College for Women University.

2. Final Year Student Pharm-D, Institute of Pharmacy, Lahore College for Women University

3. Pharm D.

Lahore College for Women University.

4. Pharm D. M.Phil

Lecturer at Institute of Pharmacy, Lahore College for Women University.
}

\section{Correspondence Address:}

Zunaira Butt

514 E-Block,

Gulshan-E-Ravi, Lahore.

zunbutt73@gmail.com

Article received on:

$11 / 03 / 2017$

Accepted for publication:

23/05/2017

Received after proof reading:

03/07/2017

\section{Zunaira Butt ${ }^{1}$, Saima Shahid², Zujajah Gull ${ }^{3}$, Munaza Riaz ${ }^{4}$}

ABSTRACT... Introduction: To assess the current status of antidotes in hospital formulary \& their comparison with list of antidotes mentioned in National Essential Drug List (NEDL). Evaluation of treatments for poisoned patients and establishment of Poison Control Center (PCC). Study Design: Cross-sectional study. Setting: Different Government and Private Hospitals of Lahore. Period: 02 months (August 2015 - September 2016). Material and Methods: A detailed questionnaire was prepared for the collection of data. Data was illustrated as graphs and tables. Results: All antidotes mentioned in NEDL are present not in a single hospital of Lahore. Atropine (87\%), Flumazenil (80\%), Magnesium Sulphate (80\%) were present in majority of the hospitals. On the contrary, Penicillamine, Obidoxime and Sodium Thiosulphate were obsolete in all hospitals. Although antidotes were not fully available in both government and private hospitals of Lahore but the situation is worse in case of private hospitals. Conclusion: High cost and late procurement are the reasons for Delay in treatment of poisoned patients. Not a single Poison Control Center is present in Lahore. Affirmative actions should be taken to improve the accessibility of antidotes in hospitals. There is emergent need to establish Poison Control Center.

Key words: $\quad$ Antidotes, Poisoning, Poison Control Center, NEDL, Lahore, Pakistan.

Article Citation: Butt Z, Shahid S, Gull Z, Riaz M. Antidotes; availability and their comparison with national essential drug list in different hospitals of Lahore. Professional Med J 2017;24(7):955-959. DOI: 10.17957/TPMJ/17.3925

\section{INTRODUCTION}

Poisoning and toxic exposures are major health problems worldwide. National Essential Drug List contains medicines which are affordable and meet the criteria to fulfill the needs of people regarding health in hospitals of developing countries like Pakistan. It was first prepared in 1994 with the help of experts in the respective fields. Recently it has been revised fourth time in 2007, according to which 14 antidotes including atropine, charcoal (activated), desferioxamine, dimercaprol, flumazenil, magnesium sulphate, methionine, naloxone, neostigmine, obidoxime, penicillamine, physostigmine, pralidoxime, protamine, prussian blue, sodium calcium edetate, sodium nitrite, sodium thiosulfate should be present in all hospitals of Pakistan. ${ }^{1}$

Accidental poisoning appears to be dropping around the globe but in Pakistan results are opposite. It was $26^{\text {th }}$ reason of mortality in 1990 , becomes $22^{\text {nd }}$ by $2010 .{ }^{2}$ According to similar study conducted in Punjab, snakebite cases increased up to 3 times in Karachi during past few years. Sedatives, analgesics and antidepressants are used in greatest amount for suicide attempts. On the other hand pesticides are majorly used causative agents used for intentional poisoning in Asia especially rural areas. ${ }^{3}$

Charcoal is the first substance used as antidote in 1820 against mercuric chloride. Study reveals that after administration of charcoal, situation of the patient become worse at first. Then pulverized form of charcoal (now commonly called activated charcoal) given and patient starts recovering after first dose. ${ }^{4}$

Benzodiazepines are used mostly for intentional poisoning in Lahore, only second to wheat pills because later is more easily available in every house than former. As stated in study 
conducted in Lahore, approximately all cases of benzodiazepine are fully recovered. ${ }^{5}$

In Pakistan, there is an urgent need to establish Poison Control Centers in all cities. Pakistan's first registered Poison Control Center is established in Karachi. Effective care can be provided to poisoned patients through a systematic provision of telephone consultation service to standardize poisoning related healthcare costs. ${ }^{6}$

\section{METHOD}

A cross-sectional study was conducted in emergency departments of different hospitals of Lahore. The duration of study was 2 months (August 2015- September 2015). Sample was collected through Random Convenient Sampling Technique.

A detailed structured questionnaire having two parts i.e., A and B was designed for physician and pharmacist respectively to collect the information about the availability of antidotes, treatment given to poisoned patients and whether PCC is established or not. Physicians and pharmacists of emergency departments interviewed. Data collection form covered the different aspects regarding hospital's formulary, supportive care, procurement method and reason of unavailability of antidotes and PCC. Verbal informed consent was taken and confidentiality was maintained. Collected data was concluded and the frequency and percentages were calculated. Statistics was applied using Microsoft Excel ${ }^{\circledR}$ and results were presented as tables and graphs.

\section{RESULTS}

The most admitted gender in poisoning cases was female having age group of 11-30yrs. The main cause of poisoning is intake of central nervous system (CNS) medications i.e., benzodiazepines, sedatives and hypnotics. Other toxic agents include organophosphates and Paracetamol.

Most common antidotes present in hospitals were Atropine, Flumazenil, Magnesium sulfate, Naloxone, Neostigmine, Activated Charcoal and Sodium Nitrate (Figure-1).

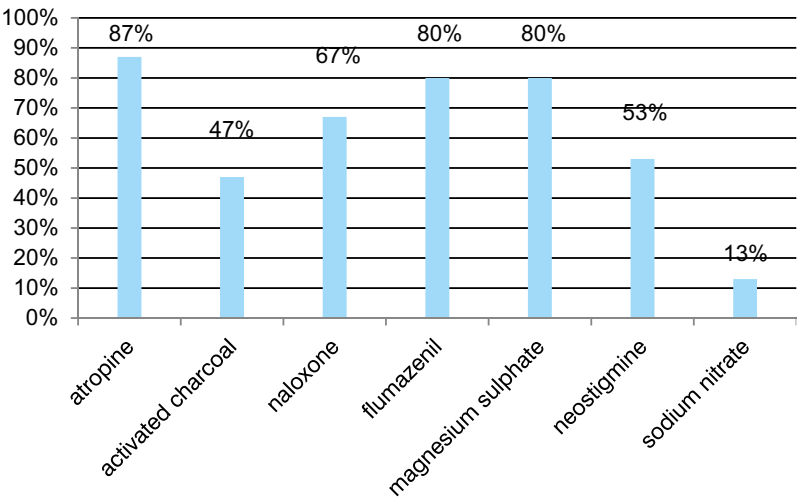

Figure-1. Availability of antidotes. Results Are Evaluated By Considering Each Group As 100\%

On the contrary, Penicillamine, Obidoxime and Sodium Thiosulphate were obsolete in all hospitals. There is absolutely no separate record keeping process for antidotes in any hospital.

Poison Control Center was not present in any hospital of Lahore.

After administering antidote, drugs like emetics (ipecac) cathartics (sorbitol) were given as additional treatment.

Life support system, Elimination enhanced instruments and Equipment for decontamination was present as supportive care in almost all hospitals (Figure-2).

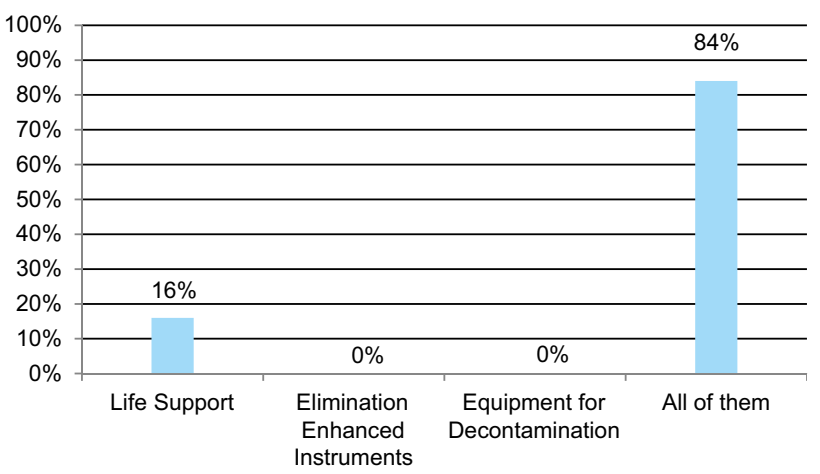

Figure-2. Availability of supportive care.

Responses of physicians regarding knowledge about antidotes are listed in Table-I

Responses of pharmacist regarding antidotes mentioned in Table-II. 


\section{Questions}

What is the peak poisoning time in a year?

What antidote is indicated if reason of poisoning is unknown?

Is it effective?

Most effective antidote against Paracetamol Poisoning?

Any Committee present in hospital which ensure availability of antidotes at the lowest cost possible?
Response

April- September

Remain same whole year

Universal Antidote

Charcoal

Normal Saline

Acc. To symptoms

Yes

$\mathrm{N}$-acetylcysteine

No
Frequency $(n=17)$

11

6

4

9

2

2

17

17

17

Table-I.

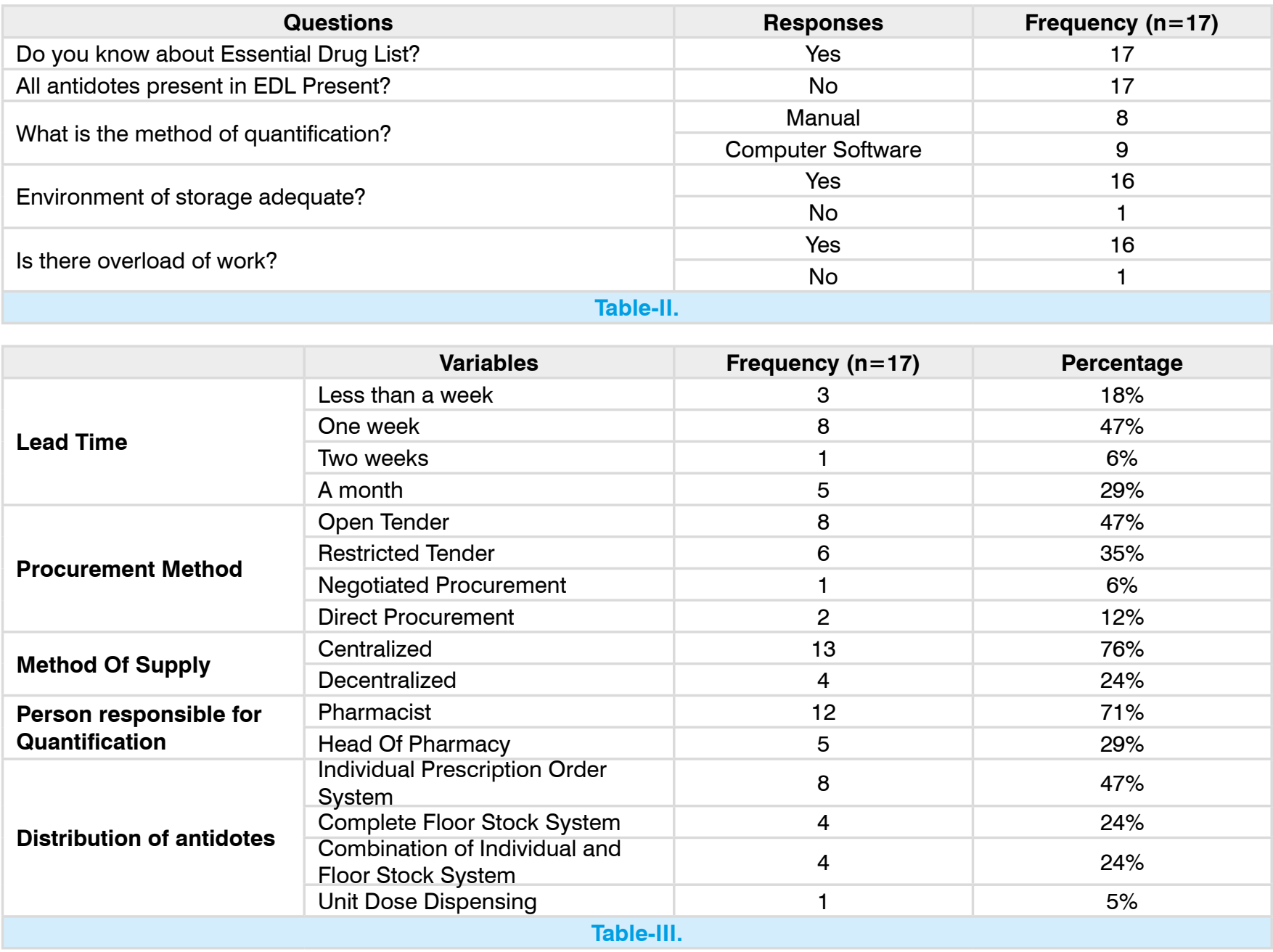

Procedure through which antidotes get available in hospitals includes Lead time, Procurement method, Method of Supply, Person responsible for quantification and Method of Distribution.

\section{DISCUSSION}

A poison is any material that cause harm to living organisms. Result of study depict female as most admitted gender (11-30 years). The main cause of poisoning is intake of central nervous system (CNS) medications i.e., benzodiazepines, sedatives and hypnotics. According to a study conducted in a tertiary care hospital in Karachi 95\% patients used self-poisoning for 
Deliberate Self Harm. Out of which $47.3 \%$ used benzodiazepines for self-poisoning. ${ }^{7}$ Other toxic agents include organophosphates and Paracetamol. Flumazenil and Pralidoxime are given through Injection route in benzodiazepine and organophosphorus poisoning respectively. A study on benzodiazepine poisoning describes that forced diuresis and dialysis techniques are not indicated because they will not remarkably accelerate the elimination of these agents. Intravenous administration of flumazenil, a pure benzodiazepine antagonist, effectively reverses benzodiazepine-induced CNS depression. ${ }^{8}$ There is also a study on organophosphorus poisoning in which, like present study, pralidoxime is the most widely recommended. ${ }^{9} \mathrm{~N}$-acetylcysteine is used in Paracetamol poisoning in almost all hospitals. According to a Sri Lankan study, post ingestion time is an important determinant of preferred antidotal therapy for acute paracetamol poisoning patients. $\mathrm{N}$-acetylcysteine is not proved to be cost effective to use in all patients. On economic grounds, methionine should become the preferred antidote. ${ }^{10}$

Most commonly antidotes present in hospital formulary are atropine, activated charcoal, naloxone, flumazenil, magnesium sulfate, neostigmine and sodium nitrate. As stated in a study conducted in Punjab, among antidotes mentioned in NEDL, Atropine (41.11\%), activated charcoal (100\%), Flumazenil (29.42\%), Naloxone (65\%), Physostigmine (6\%), Pralidoxime (35.29\%), Protamine (11.76\%) were present. $^{3}$ Each pharmacist working has the knowledge of Essential Drug List. Same results found in another study conducted in China. ${ }^{11}$ However implementation of essential drug list is a common problem in both countries. The main reason of unavailability is short shelf life (charcoal), lack of demand (obidoxime), same indication (physostigmine and neostigmine). To reduce this problem, there should be a separate committee which ensure safety and cost effectiveness of drugs. A study was conducted in New Zealand in which a small number of poisoning cases was the major cause cited for not stocking antidotes, followed by high cost. ${ }^{12}$
If the reason of poisoning is unknown, 9 out of 17 physicians indicate pulverized charcoal instead of universal antidote. Picchioni also stated same that activated charcoal alone is more effective than universal antidote. ${ }^{13}$ If situation get more complicated after giving antidote, emetics are used in $42 \%$ of cases. Other common treatment includes diuretics and antiarrhythmic. Mostly it depends on patient's condition and causative agent. Resources include life support, elimination enhanced instruments and equipment for decontamination, are present. General cares provided to the poisoned patients include assisted ventilation and fluid depletion. Dialysis is used in very critical conditions. Marraffa et al. concluded that identification of the toxic substance, to which the patient has been exposed, is vital before administration of any antidote. Patients should never be given anything to induce vomiting, as it could cause significant damage to the person's throat, esophagus, or mouth. ${ }^{14}$

Methods of procurement used mostly are Open and Restricted Tender. Direct procurement (local purchase) also used in some of hospitals. A study done by Godeliver A.B. Kagashe in which lack of funds to procure the medicines was one of the main reasons contributing to stock outs. Poor knowledge in logistics is also another factor. ${ }^{15}$ Therapeutic committee is present in $44 \%$ hospital whose work is to decide which drugs will appear on that entity's drug formulary. According to a study conducted in Karachi, there are two registered PCCs in Pakistan that are located in Karachi (Sindh province) and Faisalabad (Punjab Province). ${ }^{2}$ Our study showed that PCC is not present in Lahore City.

\section{CONCLUSION}

Poisoning cases are mostly medico-legal cases. That's why they are handled by government settings. However, if admitted in private settings, patients are stabilized and referred to nearest government hospitals. It is concluded that private hospitals of the Lahore City do not stock adequate supply of antidotes. Some hospitals have no antidote at all. Antidotes like Flumazenil and Charcoal is present in most of hospitals 
settings. Treatment is given according to patient's condition. No trace of PCC is present in any hospital. Immediate actions needed to be taken for establishment of PCC in Lahore.

\section{Copyright@ 23 May, 2017.}

\section{REFERENCES}

1. Ministry of Health. National Essential Drug List of Pakistan [Internet]. 2003. [cited 01 March 1, 2017] Available from http://www.pcdapakistan.com/ documents/nedl.pdf.

2. Khan NU, Pérez-Núñez R, Shamim N, Khan UR, Naseer $\mathrm{N}$, Feroze A, Razzak JA, Hyder AA. Intentional and unintentional poisoning in Pakistan: a pilot study using the Emergency Departments surveillance project. Bmc emergency medicine. 2015; 15(2):S2.

3. Arslan N, Khiljee S, Bakhsh A, Ashraf M, Maqsood I. Availability of antidotes and key emergency drugs in tertiary care hospitals of Punjab and assessment of the knowledge of health care professionals in the management of poisoning cases. Pak J Pharm Sci. 2016; 29(2):603-7.

4. Flanagan R, Jones A, Maynard RL. Antidotes: principles and clinical applications. CRC Press; 2003 Sep 2. 1st Ed. P: 17.

5. Shoaib S, Nadeem MA, Khan ZU. Causes and outcome of suicidal cases presented to a medical ward. Annals of KEMU. 2016; 11(1).

6. Khan NU, Mir MU, Khan UR, Khan AR, Ara J, Raja K, Mirza FH. The Current State of Poison Control Centers in Pakistan and the Need for Capacity Building. Asia Pac J Med Toxicol. 2014;3(1):31.

7. Abidi M, Zia W, Waqas M. Deliberate self harm: A local perspective. J Pak Psychiatry Soc. 2010; 7:67.

8. Gaudreault P, Guay J, Thivierge RL, Verdy I. Benzodiazepine poisoning. Drug Safety. 1991; 6(4):247-65.

9. Minton NA, Murray VS. A review of organophosphate poisoning. Medical toxicology and adverse drug experience. 1988; 3(5):350-75.

10. Shen Q, Yang C, Chang J, Wu L, Zhu W, Lv B, Ye D, Yang $S$, Fang Y. Hospital pharmacists' knowledge of and attitudes towards the implementation of the National Essential Medicines System: a questionnaire survey in western China. BMC Health Services Research. 2016; 16(1):292.

11. Abbott V, Creighton M, Hannam J, Vincent T, Coulter C. Access in New Zealand to antidotes for accidental and intentional drug poisonings. Aust $\mathrm{J}$ Prim Health. 2012; 4(2):100-5.

12. Daly JS, Cooney DO. Interference by tannic acid with the effectiveness of activated charcoal in "Universal Antidote". Clinical toxicology. 1978; 12(5):515-22.

13. Marraffa JM, Cohen V, Howland MA. Antidotes for toxicological emergencies: a practical review. $\mathrm{Am} \mathrm{J}$ Health Syst Pharm. 2012; 69(3):199-212.

14. Senarathna SG, Ranganathan SS, Buckley N, Fernandopulle R. A cost effectiveness analysis of the preferred antidotes for acute paracetamol poisoning patients in Sri Lanka. BMC clinical pharmacology. 2012; 12(1):6.

15. Kagashe GA, Massawe T. Medicine Stock Out and Inventory Management Problems in Public Hospitals in Tanzania: A Case of Dar Es Salaam Region Hospitals. Int. J. Pharm. 2012; 2(2):252-9.

\section{AUTHORSHIP AND CONTRIBUTION DECLARATION}

\begin{tabular}{|c|c|c|c|}
\hline Sr. \# & Author-s Full Name & Contribution to the paper & Author $=s$ Signature \\
\hline 1 & Zunaira Butt & $\begin{array}{l}\text { Study concept \& design } \\
\text { data collection \& analysis } \\
\text { Manuscript \& review }\end{array}$ & \\
\hline 2 & Saima Shahid & Data collection \& analysis & \\
\hline 3 & Zujajah Gull & Data collection \& analysis & \\
\hline 4 & Munaza Riaz & $\begin{array}{l}\text { Supervision of data, } \\
\text { collection \& manuscript } \\
\text { writing }\end{array}$ & \\
\hline
\end{tabular}

